Endocrinol. Japon. 1988, 35 (2), 303-310

\title{
Prolactin Release in Polycystic Ovarian Syndrome
}

\author{
Hisanori MiNAKAMI, NaOHide ABE, Naoko OKA, Kozo KIMURA, \\ TAKASHI TAMURA AND TARO TAMADA
}

\author{
Department of Obstetrics and Gynecology, Jichi Medical School, \\ Minamikawachi-machi Tochigi-ken, 329-04 Japan
}

\begin{abstract}
s
To evaluate the prevalence of hyperprolactinemia in patients with polycystic ovarian syndrome (PCO), 72 patients with oligo- or anovulation were studied. All of the patients had persisting elevated $\mathrm{LH}(>25 \mathrm{mIU} / \mathrm{ml})$, normal FSH, high $\mathrm{LH} / \mathrm{FSH}$ ratio $(>2.5)$, and exaggerated LH responses to LHRH. Mean testosterone and androstenedione concentrations were appreciably increased in these patients. Out of 171 samples for prolactin (PRL) determination from these 72 patients, only 5 patients had a PRL value above $30 \mathrm{ng} / \mathrm{ml}$ during the first sampling. The next sampling from these same 5 women disclosed that they were transiently hyperprolactinemic because the next samples showed a normal PRL value. To further investigate the PRL secretory capacity $500 \mu \mathrm{g}$ of TRH and $10 \mathrm{mg}$ of metoclopramide (MCP) were administered to these 72 and 44 patients, respectively. The PRL response to MCP was significantly blunted in these patients compared to normal women while the PRL response to TRH in these patients was not indistinguishable from that in normal women. These results indicate that the true prevalence rate of hyperprolactinemia in PCO may be low rather than high and the association of hyperprolactinemia with PCO may be coincidental rather than a pathogenically related phenomenon.
\end{abstract}

Basal serum PRL levels have been reported to be elevated in one-third of patients with PCO (Alger et al., 1980, Carmina et al., 1984., Duignan 1976, Luciano et al., 1984). One of the postulated mechanisms which associates elevated PRL with PCO is an abnormal central neurotransmitter, particularly in the dopaminergic control of PRL release (Corenblum and Taylor 1982, Luciano et al., 1984). Hypothalamic dopamine is known to be the major factor inhibiting PRL secretion. Since LH

Received September 22, 1987

Correspondence should be addressed to HISANORI MINAKAMI has also been reported to be suppressed by dopamine (Ferrari et al., 1981, Leblanc et al., 1976, Pehrson et al., 1983), dopamine deficiency may result in hyperprolactinemia and an increase in LH. However, it was demonstrated recently that dopamine can stimulate in vitro release of GnRH from the adult human hypothalamus (Rasmussen et al., 1986). Further, dopamine antagonist metoclopramide (MCP) was shown to reduce LH in rhesus monkeys (Kaufman et al., 1985). Since these observations indicate the stimulatory role of dopamine in LH release, they are clearly against the hypothesis that deficient hypothalamic dopamine may play a role in the high prevalence of hyper- 
prolactinemia in PCO. We undertook to reevaluate the secretory capacity of $P R L$ in PCO patients.

\section{Materials and Methods}

Seventy-two patients with an established clinical and laboratory diagnosis of PCO were studied. Their ages were between 18 and 36 years. The condition was diagnosed on the basis of infrequent or absent ovulation. In addition, all of the patients included in this study persistent elevated LH ( $>25 \mathrm{mIU} / \mathrm{ml})$, normal FSH, a high LH/FSH ratio $(>2.5)$ and exaggerated $\mathrm{LH}$ responses to LHRH. The 56 healthy and regularly menstruating women served as the control.

Basal LH, FSH, testosterone, androstenedione and PRL secretion

Random serum LH, FSH, testosterone (T'sterone), androstendione (A'dione) and PRL were evaluated 189, 189, 93, 86 and 171 times, respectively, in 72 patients with PCO. These T'sterone and A'dione concentrations were compared with those, determined randomly in 52 normal women. Basal PRL was compared with that in 11 normal women throughout their 11 cycles.

\section{$L H$ and FSH responses to $L H R H$}

A $100 \mu \mathrm{g}$ of LHRH test (intramuscularly) was performed in 72 patients with PCO. These results were compared with those in 25 normal women examined in the mid-follicular phase.

\section{PRL stimulation tests}

$500 \mu \mathrm{g}$ of TRH was administered intramuscularly to 72 patients with PCO. These results were compared with those obtained in 18 normal women examined in the mid-follicular phase. In addition, an intravenous $10 \mathrm{mg}$ of MCP test was performed in 44 out 72 patients with PCO. These results were compared with those obtained in 12 normal women examined in the mid-follicular phase and 16 normal women examined in the mid-luteal phase.

Serum was removed and frozen until assayed. Serum LH, FSH, and PRL were determined by radioimmunoassay as previously described (Minakami et al., 1984, 1986). Intra- and interassay coefficients of variation for $\mathrm{LH}$, FSH, and PRL did not exceed $7 \%$ and $11 \%$, respectively. Testosterone (T'sterone) and androstenedione (A'dione) levels were determined by radioimmunoassay at Special Reference Lab. (Japan). Intra- and interassay coefficients of variation for $\mathrm{T}$ 'sterone were $4.1 \%$ and $12.2 \%$, respectively. Those for A'dione were $9.0 \%$ and $10.9 \%$, respectively. Statistical analyses were performed by means of Student's $t$-test.

\section{Results}

Fig. 1 shows the basal $\mathrm{LH}$ and FSH levels in 72 patients with PCO. The mean $( \pm$ SD) basal levels of $\mathrm{LH}$ and FSH were $41.5 \pm 13.2$ and $11.6 \pm 2.6 \mathrm{mIU} / \mathrm{ml}$, respectively.

LH and FSH responses after a $100 \mu \mathrm{g}$ intramuscular injection of LHRH are shown in Fig. 2. The mean LH ( $\pm \mathrm{SE})$ concentrations before and after LHRH administration were significantly elevated $(\mathrm{p}<$ 0.001 ) in the 72 patients with PCO while the FSH concentrations were indistinguishable from those found in 25 normal women.

Basal T'sterone and A'dione concentrations are shown in Fig. 3. A considerable number of patients had high T'sterone and/or A'dione. Consequently, the mean $( \pm \mathrm{SD})$ concentrations of T'sterone $(1.06 \pm$ $0.51 \mathrm{ng} / \mathrm{ml})$ and A'dione $(1.44 \pm 0.81 \mathrm{ng} / \mathrm{ml})$ in $\mathrm{PCO}$ were significantly higher than those $(0.80 \pm 2.4 \mathrm{ng} / \mathrm{ml}$ and $0.82 \pm 0.41 \mathrm{ng} / \mathrm{ml})$ found in normal women.

Fig. 4 shows basal PRL in patients with PCO and normal women. Eighty and ninetyseven determinations of PRL during the follicular and luteal phases of 11 apparently normal women served as the control. Even in normal women, 8.5 per cent of the samples collected throughout the entire menstrual cycle showed high PRL $(>30 \mathrm{ng} /$ $\mathrm{ml}$ ). In contrast, only 5 out of 171 samples (2.9\%) showed a PRL concentration above $30 \mathrm{ng} / \mathrm{ml}$ in PCO. Further, these mild hy- 


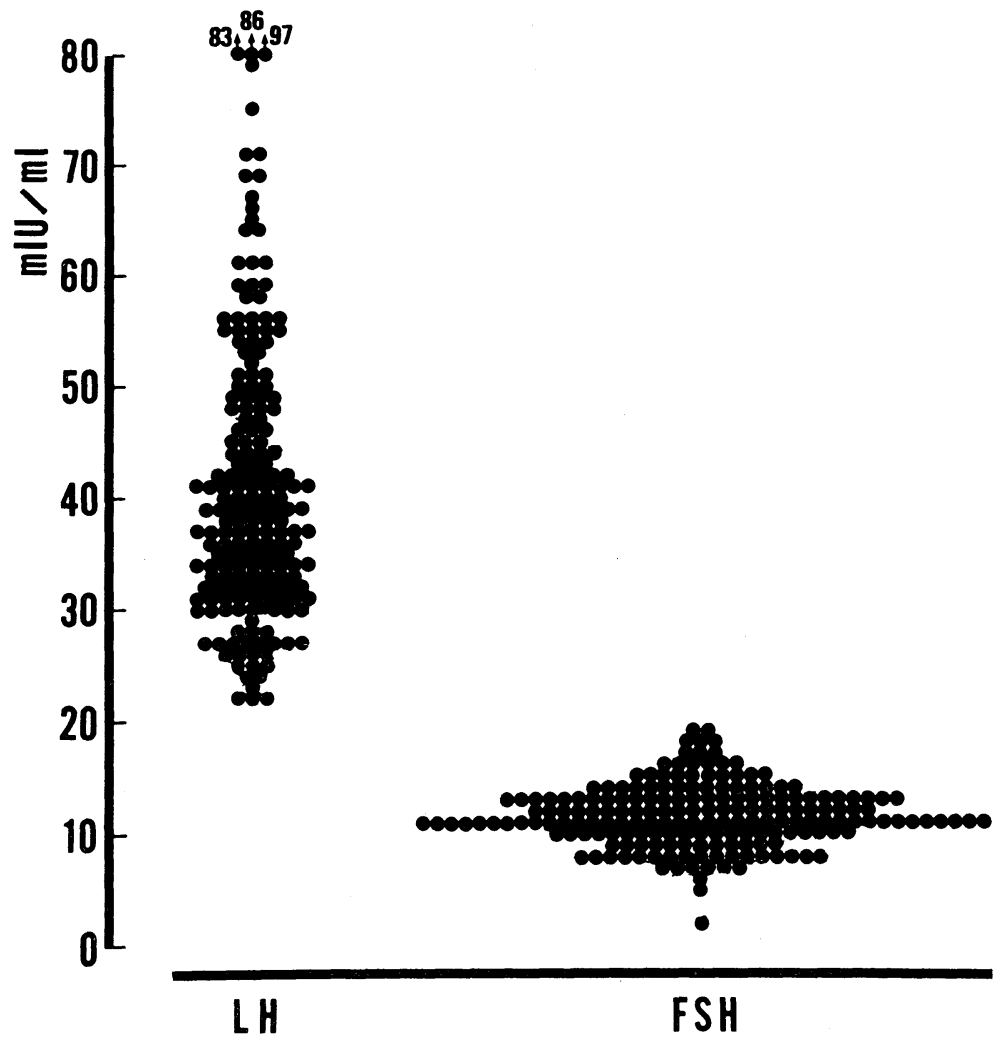

Fig. 1. One-hundred and eighty-nine determinations of basal $\mathrm{LH}$ and FSH in 72 PCO patients.

Fig. 2. LH and FSH responses after an administration of $100 \mu \mathrm{g}$ of LHRH in 72 patients with PCO and 25 normal women.

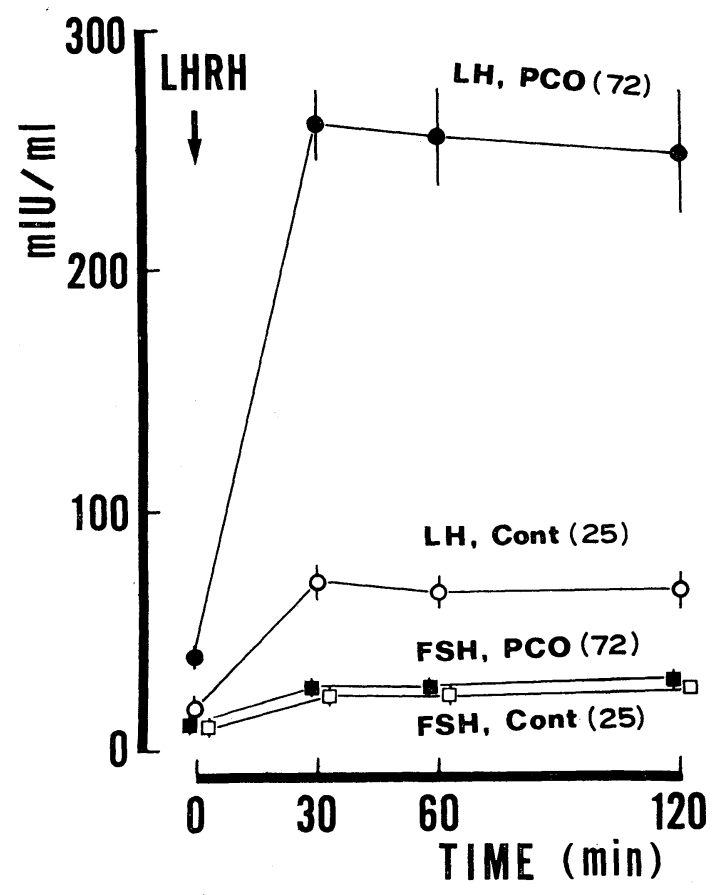


Fig. 3. Serum testosterone and androstenedione in 72 PCO patients are contrasted to those in 52 normal women.

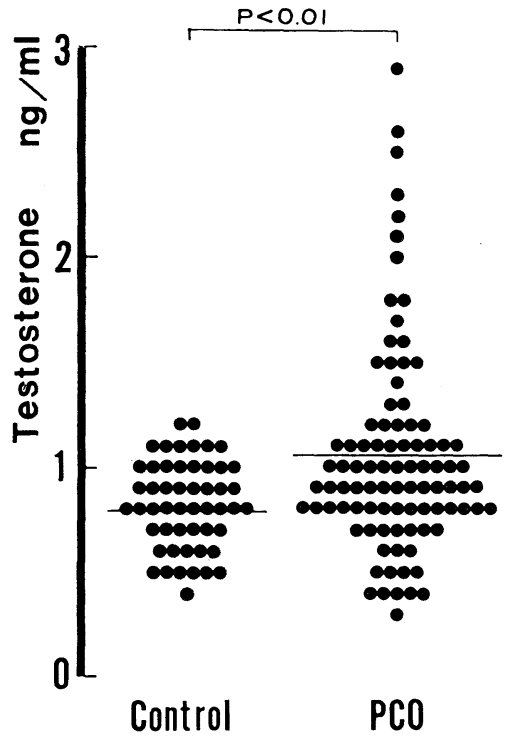

Control

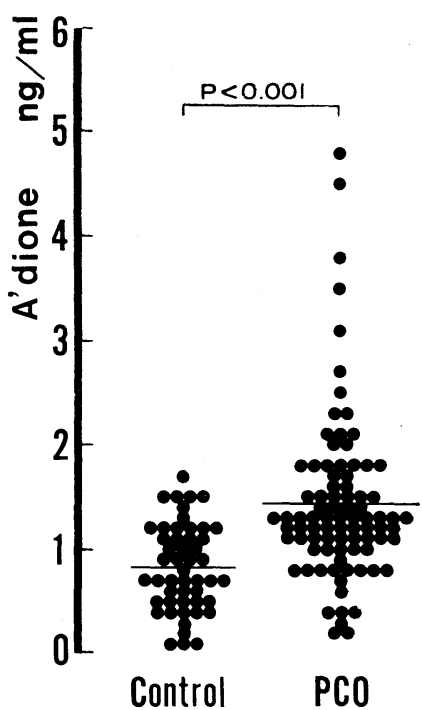

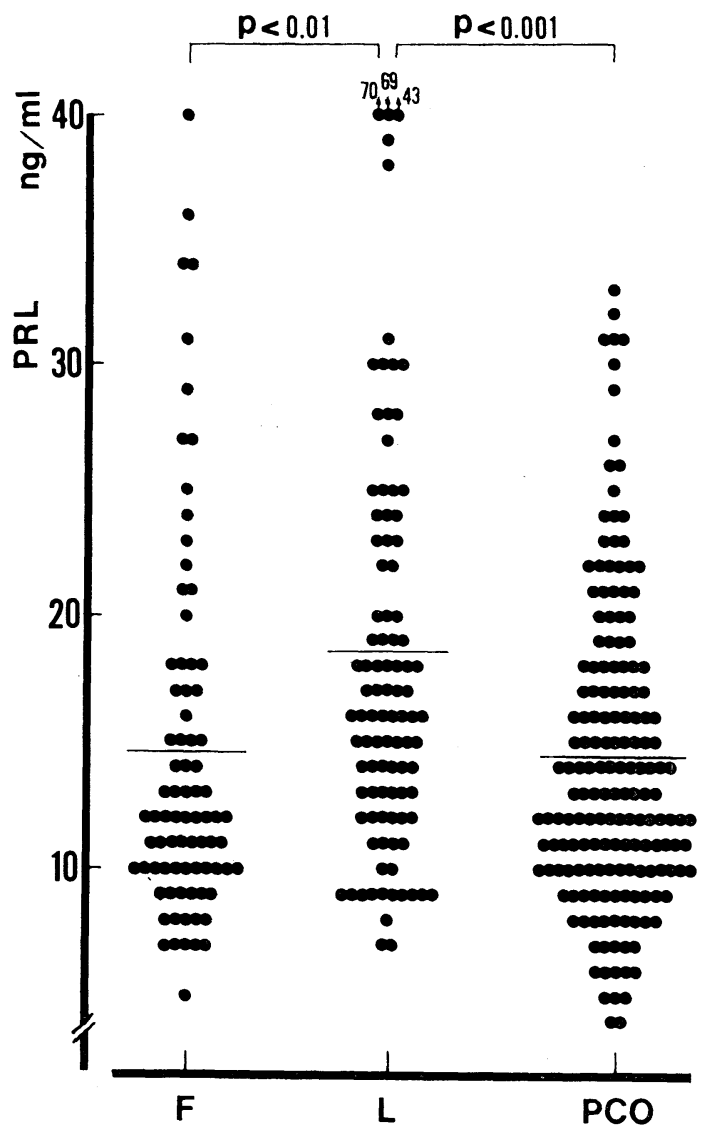

Fig. 4. One-hundred and seventy-one determinations of PRL in 72 PCO patients are contrasted with 80 and 97 determinations for PRL sampled during the follicular phase and the luteal phase during 11 cycles of 11 normal women. $F$ refers to the follicular phase and $\mathrm{L}$ to the luteal phase. 


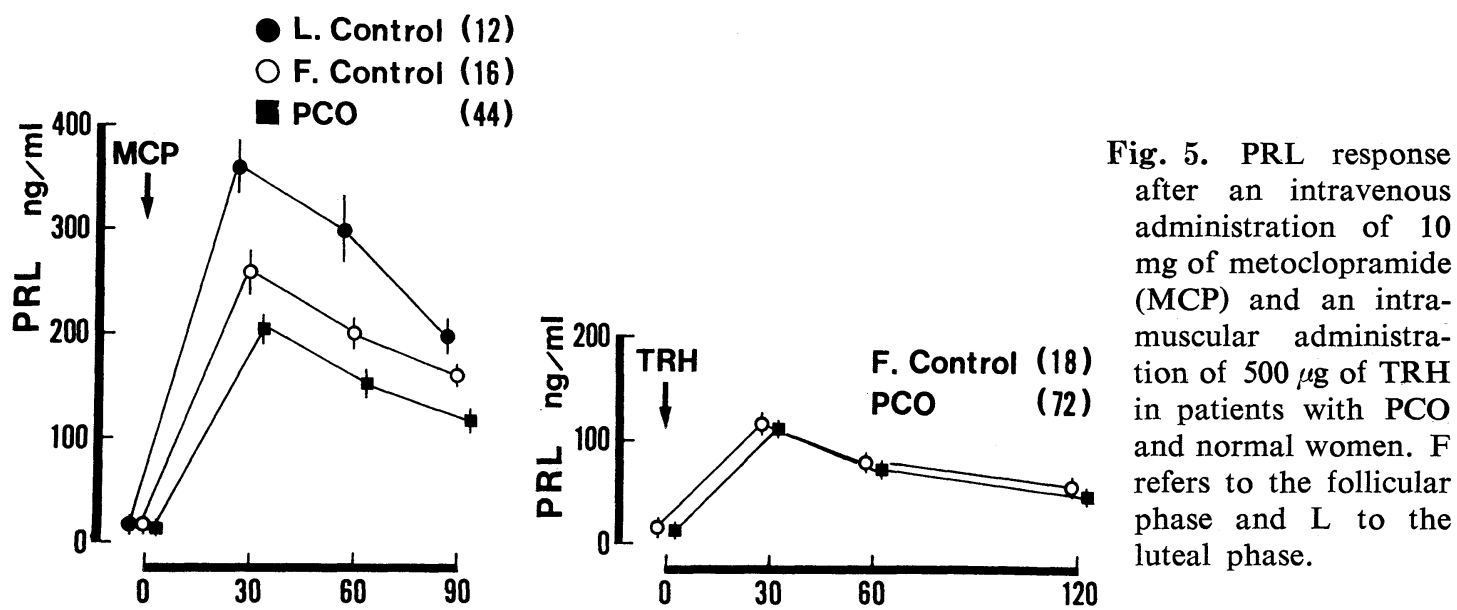

TIME (min)

perprolactinemia cases were transient because the next 5 samples from these 5 women showed normal PRL.

The response of PRL to lactotrope stimulating agents MCP and TRH is shown in Fig. 5. A blunted PRL response after a $10 \mathrm{mg}$ intravenous MCP administration was observed in PCO patients when compared to normal women, while the PRL response to TRH in PCO patients was indistinguishable from that in normal women. When compared with the control group examined in the luteal phase, the PRL concentrations after MCP administration in PCO were significantly $(\mathrm{p}<0.001)$ low at any time. When compared with the control group examined in the follicullar phase, the PRL values at 30,60 , and 90 minutes after MCP administration in PCO patients were significantly low at $\mathrm{p}<0.02, \mathrm{p}<0.05$, and $\mathrm{p}<0.02$, respectively.

\section{Discussion}

Earlier, many authors observed the higher incidences of hyperprolactinemia in patients with PCO (Alger et al., 1980, Carmina et al., 1984, Duignan 1976, Luciano et al., 1984). In the present study, we demonstrated that none of the 72 PCO patients had persistently increased basal PRL. One explanation for this discrepancy may be patient selection. There is an inconsistency in the diagnosis of PCO. Sometimes in clinical and biochemical PCO there is no ovary enlargement (Goldzieher 1981, Yeh et al., 1987). On the other hand, multifollicularity of the ovary is sometimes found in anovulatory patients who are apparently different from PCO cases (Adams et al., 1985, Givens 1984). Givens (1984) insisted that morphological polycystic ovary was the final expression of several specific entities and thus was a sign and not a specific diagnosis. Therefore the detection of enlarged ovary by palpation or ultrasonography may not be essential to diagnosis as Goldzieher (1981) says. Despite the difference in diagnostic criteria, similarities in the hormonal profile found in our PCO patients with other studies indicate that we are dealing with the same pathology. Even taking into account an inclusion of a heterogenous group of oligo-anovulation in this study, our result shows that none of 
the patients studied were complicated by persisting hyperprolactinemia which suggests that hyperprolactinemia may be seldom found in PCO. Similar findings were obtained recently by Murdoch et al., (1986). It is also of interest to note that MCP caused a more blunted increase in PRL in PCO than in normal woman while the PRL responses to TRH did not differ in $\mathrm{PCO}$ and normal women.

Although both PRL and thyrotropin (TSH) are known to be suppressed by dopamine (Morley, 1981), it has been reported that the PRL response to MCP was decreased while at the same time the TSH response was increased in patients who were considered to have increased central dopamine activity (DeMarinis et al., 1984). Further, there are several reports which indicate an association between increased dopamine activity and attenuated PRL response to a dopamine receptor blockade (Quigley et al., 1979, Scanlon et al., 1981). Recently, Agner et al., (1986) reported that the infusion of dopamine reduced the PRL response to $\mathrm{MCP}$ in normal menstruating women in the follicular phase. The pathophysiological importance of their report is that their experiments may provide evidence of an association between increased dopamine activity and diminished PRL responses to a dopamine receptor blockade. If this is the case, central dopamine activity may be high rather than low in PCO and the reportedly high prevalence of hyperplolactinemia in PCO could not be explained by the deficient central dopamine. In addition, it might be speculated that longstanding increased central dopamine activity may selectively decrease the amount of PRL which should be released in response to dopamine receptor blocking agents.

The concept of a suppressive role of central dopamine in the control of $\mathrm{LH}$ release has been supported by the observation that peripherarily administrated dopamine reduced basal LH in normal and hypo- gonadal women (Ferrari et al., 1981, Leblanc et al., 1976, Pehrson et al., 1983). These effects of dopamine have been believed to act via LHRH suppression because LH response to LHRH was unchanged during dopamine infusion (Pehrson et al., 1983). The exaggerated decrease in serum $\mathrm{LH}$ after dopamine administration observed in $\mathrm{PCO}$ by Quigley et al., (1981) further supported the theory of a central dopamine deficiency as a cause of an increase in $\mathrm{LH}$ in PCO. However, it was reported by Kaufman et al., (1985) that the dopaminergic blocking agent MCP reduced the frequency of LHRH pulse generator activity, resulting in decreased LH in rhesus monkeys. Kaufman's report (1985) indicates that endogenous dopamine may play a facilitory role in the control of pulsatile LH release. In PCO patients, the frequency of LH pulses is reportedly increased, resulting in an increase in $\mathrm{LH}$ (Rebar et al., 1976). The high frequency of LH pulses found in PCO (Rebar et al., 1976) may result from augmented central dopamine activity. In addition, dopamine was recently reported to stimulate in vitro release of LHRH from the adult human hypothalamus by a dopomine receptor mediated mechanism (Rasmussen et al., 1986). Since these reports strongly suggest a facilitory role of central dopamine in the $\mathrm{LH}$ release by the LHRH mediated mechanism, it is difficult to accept the hypothesis that central dopamine deficiency causes an increase in LH secretion in PCO.

On the basis of our findings and the abovementioned reports, we believe that central dopamine is present and active rather than deficient in PCO patients and therefore the actual incidence of hyperprolactinemia in PCO may be low as observed in this study. The association of hyperprolactinemia with PCO may be a coincidence rather than a pathophysiologically related phenomenon. 


\section{Acknowledements}

We wish to thank Ms. Yasuko Kitagawa and Ms. Shizue Seki for Itechnical assistance, and Ms. Mariko Kato for secretarial assistance.

\section{References}

Adams, J., S. Franks, D.W. Polson, H. D. Mason, N. Abdulwahid, M. Tucker, D. V. Morris, J. Price and H. S. Jacobs (1985). Multifollicular ovaries: Clinical and endocrine features and response to pulsatile gonadotropin releasing hormone. Lancet ii, 1375-1378.

Agner, T., C. Hagen, A. N. Andersen and H. Djursing (1986). Increased dopaminergic activity inhibits basal and metoclopramidestimulated prolactin and thyrotropin secretion. J. Clin. Endocrinol. Metab. 62, 778-782.

Alger, M., L. Vazquez-Matute, M. Mason, E. S. Canales and A. Zarate (1980). Polcystic ovarian disease associated with hyperprolactinemia and defective metoclopramide response. Fertil. Steril. 34, 70-71.

Carmina, E., F. Rosato, M. Maggiore, A. M. Gagliano, D. Indovina and A. Janni (1984). Prolactin secretion in polycystic ovary syndrome (PCO): Correlation with the steroid pattern. Acta. Endocrinol. (Copenh) 105, 99104.

Corenblum, B. and P. J. Taylor (1982). The hyperprolactinemic polycystic ovary syndrome may not be a distinct entity. Fertil. Steril. 38, 549-552.

DeMarinis, L., A. Mancini, G. Maira, C. Anile, E. Merini and A. Barbarino (1984). Postoperative evaluation of dopaminergic tone in prolactinoma patients. II. Plasma thyrotropin response to metoclopramide. J. Clin. Endocrinol. Metab. 58, 405-409.

Duignan, N. M. (1976). Polycystic ovarian disease. Br. J. Obstet. Gynaecol. 83, 593602.

Ferrari, C., P. Rampini, A. Malinverni, C. Scarduelli, R. Benco, R. Caldara, C. Barbieri, G. Testori and P. G. Crosignani (1981). Inhibition of luteinizing hormone release by dopamine infusion in healthy women and in various pathophysiological conditions. Acta. Endocrinol. (Copenh) 97, 436-440.
Givens, J. R. (1984). Polycystic ovaries- a sign, not a diagnosis. Semin Reprod. Endocrinol. 2, 271-280.

Goldzieher, J. W. (1981). Polycystic ovarian disease, Fertil. Steril. 35, 371-394.

Kaufman, J.-M., J. S. Kesner, R. C. Wilson and E. Knobil (1985). Electro-physiological manifestation of luteinizing hormone-releasing hormone pulse generator activity in the rhesus monkey: Influence of $\alpha$-adrenergic and dopaminergic blocking agents. Endocrinology 116, 1327-1333.

Leblanc, H., G. C. L. Lachelin, S. Abu-Fadil and S. S. C. Yen (1976). Effects of dopamine infusion on pituitary hormone secretion in humans. J. Clin. Endocrinol. Metab. 43, 668674.

Luciano, A. A., K. K. Chapler and B. M. Sherman (1984). Hyperprolactinemia in polycystic ovary syndrome. Fertil. Steril. 41, 719725.

Minakami, H., K. Kimura, K. Ijima, A. Akabori and T. Tamada (1986). Evaluation of GnRH administration on the prolactin response to thyrotrophin-releasing hormone in normal women. Endocrinol. Japon. 33, 511-517.

Minakami, H., K. Kimura, H. Yano, T. Kanazawa and T. Tamada (1984). The effects of progesterone on gonadotrophin release in hypogonadal women. Acta. Endocrinol. (Copenh) 107, 456-461.

Morley, J. E. (1981). Neuroendocrine control of thyrotropin secretion. Endocrine. Rev. 2, 396-436.

Murdoch, A. P., W. Dunlop and P. KendallTaylor (1986). Studies of prolactin secretion in polycystic ovary syndrome. Clin. Endocrinol. 24, 165-175.

Pehrson, J. J., W. L. Jaffee and J. L. Vaitukaitis (1983). Effect of dopamine on gonadotropinreleasing hormone-induced gonadotropin seeretion in postmenopausal women. J. Clin. Endocrinol Metab. 56, 889-892.

Quigley, M. E., S. J. Judd, G. B. Gilliand and S. S. C. Yen (1979). Effects of a dopamine antagonist on the release of gonadotropin and prolactin in normal women and women with hyperprolactinemic anovulation. J. Clin. Endocrinol. Metab. 48, 718-720.

Quigley, M. E., J. S. Rakoff and S. S. C. Yen (1981). Increased luteinizing hormone sensitivity to dopamine inhibition in polycystic ovary syndrome. J. Clin. Endocrinol. Metab. 
$52,231-234$

Rasmussen, D. D., J. H. Liu, P. L. Wolf and S. S. C. Yen (1986). Gonadotropin-releasing hormone neurosecretion in the human hypothalamus: In vitro regulation by dopamine. J. Clin. Endocrinol. Metab. 62, 479-483.

Rebar, R., H. I. Hudd, S. S. C. Yen, J. Rakoff, G. Vandenberg and F. Naftolin (1976). Characterization of the inappropriate gonadrotropin secretion in polycystic ovary syndrome. $J$. Clin. Invest. 57, 1320-1329.
Scanlon, M. F., Rodriguez-Arnao, A. M. McGregor, D. Weightman, M. Lewis, D. B. Cook, A. Gomez-Pan and R. Hall (1981). Altered dopaminergic regulation of thyrotrophin release in patients with prolactinomas : Comparison with other tests of hypothalamicpituitary function. Clin. Endocrinol. 14, 133143.

Yeh, H.-C., W. Futterweit and J. C. Thornton (1987). Polycystic ovarian disease : US features in 104 patients. Radiology. 163, 111-116. 